\title{
Mental Health in Cypriot Citizens of the Rural Health Centre Kofinou
}

\author{
Georgios Stavrou ${ }^{1,2, *}$, Lefkios Paikousis ${ }^{3}$, Eleni Jelastopulu ${ }^{4}$ and Georgios Charalambous ${ }^{5}$ \\ 1 Department of Pharmacy, Rural Health Centre Kofinou, Larnaca 7735, Cyprus \\ Health Management, Frederick University, Nicosia 1036, Cyprus \\ Independent Researcher, Nicosia 1048, Cyprus; lefkiospaik@yahoo.co.uk \\ Department of Public Health, Medical School, University of Patras, Patras 26500, Greece; jelasto@upatras.gr \\ 5 Department of Emergency Medicine, General Hospital of Athens "Hippocration”, Athens 11527, Greece; \\ drcharalambous@yahoo.gr \\ * Correspondence: grgpharm@gmail.com; Tel.: +357-99-136500
}

Academic Editor: Sampath Parthasarathy

Received: 7 August 2016; Accepted: 27 October 2016; Published: 1 November 2016

\begin{abstract}
Objective: The main purpose of this study was to investigate the mental health of Cypriot citizens living in the current difficult period of economic recession. The specific objective was to investigate the different factors (gender, age, socio-economic factors, etc.) that may affect the levels of emotional distress, anxiety, and depression in patients attending the Rural Health Centre of Kofinou. Materials and Methods: The sample consisted of a total of 300 Cypriots who visited Kofinou Health Centre in the period between July and September 2015. For the middle-aged citizens, the Greek version of the Hospital Anxiety Depression Scale (HADS) was applied to 150 persons [1], while for the visiting senior citizens (aged over 65 years), the Greek version of the Geriatric Depression Scale (GDS) was used [2]. Results: HADS: A total of 150 people of average age $47 \pm 11.5$ years (min 23-max 64) participated in the study. Fifty-six percent were women. Seventy-seven percent stated they had a reduction in income (mean reduction $35 \% \pm 25 \%$ ) and $46.7 \%$ suffered from chronic disease. The $36.6 \%$ and $28.7 \%$ of the visitors showed moderate or severe forms of anxiety and depression, accordingly. Higher emotional distress is associated with lower educational level $(b=-2.63, p<0.001)$, lower income $(b=-1.07, p=0.017)$, and the presence of a chronic disease $(b=5.45, p<0.001)$. The same factors are significantly associated with higher anxiety (Education: $b=-1.20, p=0.003$; Income: $\mathrm{b}=-0.64, p=0.01$; Chronic disease: $\mathrm{b}=2.82, p=0.001)$. Additionally, a reduction in income $(>35 \%)$ is associated with increased depression $(p=0.028)$. GDS: 150 patients out of which 77 were women (51.3\%). The average age of participants was $72 \pm 5.5$ years. Ninety-three $(62 \%)$ participants declared a reduction in income due to the financial crisis (mean reduction $20 \% \pm 8 \%$ ), while $139(92.7 \%)$ stated that they had chronic disease. Fifty-three participants (35.3\%) thought they had symptoms of depression after the economic crisis. The women showed higher level of geriatric depression symptoms than men $(b=-1.96, p=0.005)$, while age is associated with higher levels of GDS $(b=0.16$, $p=0.006)$. Conclusions: The study shows that stress levels, depression, and emotional distress are increased in specific population groups. The main variables associated with the mental health of the participants are the presence of a chronic disease, income, and level of education.
\end{abstract}

Keywords: depression; anxiety; emotional distress; HADS; GDS; Health Centre

\section{Introduction}

It is well known and commonly accepted that issues related to mental health are directly and indirectly caused by deprivation, poverty, inequality, and many other social and financial factors. Therefore, economic recessions, which have been recorded, are still being historically documented, 
showing that the world population has high-risk periods in terms of mental health, even up to this date [3].

The economic recession that occurred in 2007 in the U.S. grew to involve the rest of the world and had a significant impact on the European Union (EU) and more specifically on Cyprus. This negative impact has led Cyprus's economy to a crucial decline, thus having a dramatic rise of the unemployment rates and leading a large number of people to live under poor conditions [4]. Simultaneously, the increase in the national debt, the agreements of the country's financial assistance facility, as well as the loan agreements have led Cyprus to apply restrictive measures and severe cuts in public spending, even within the health sector and welfare services.

The rising unemployment, reduced incomes, and the living conditions of the citizens have increased the risk of living in poverty and underprivileged conditions. Thus, citizens and predominantly young people are inevitably affected. Young people have become very anxious and fearful for the future $[5,6]$. Those same conditions also lead to suicide attempts, especially in the elderly population. Unemployment, poverty, stress, and insecurity are therefore risk factors, which constantly increase the rates of depression, therefore negatively affecting people across all ages [7].

According to the World Health Organization (WHO), depression is a universal mental disorder characterized by sadness, loss of interest or pleasure, feelings of guilt or low self-esteem, sleep deprivation or lack of appetite, and fatigue and inability to concentrate [8]. Furthermore, based on research, depression often appears at a young age and mostly affects the female population. It is important to mention that citizens who have either lost their jobs due to adverse economic conditions or have been generally made unemployed are at a higher risk of developing symptoms of anxiety and depression [9].

As a consequence of the social perceptions and attitudes of Cypriot citizens, many cases remain either undiagnosed or are not adequately addressed in the Cypriot community [4]. There is a large proportion of patients presenting with depressive syndromes who do not seek specialist psychiatric attention. Instead, they resort to traditional forms of counselling or palliative assistance, while others passively anticipate in recovering the symptoms. There are also many people visiting primary medical care services mainly for various psychosomatic symptoms. Nevertheless, clinical depression remains sub-optimally diagnosed [10].

In conclusion, this current research focuses on exploring the mental health of Cypriot citizens in the area of Kofinou Rural Health Centre (RHC) along with the various factors affecting it. Due to the lack of research in this field, it is recommended that more studies on the topic of economic crisis and its effects on the Cypriot society be carried out. It is an essential and current issue, which undoubtedly concerns not only the health services and health professionals, but also all Cypriot citizens.

\section{Materials and Methodology}

The study was cross-sectional and was carried out in the Rural Health Centre of Kofinou using two scales for estimating the mental health of patients visiting the center: the GDS and HADS, both screening tests where higher total scores indicate higher depression or anxiety symptomatology. The GDS questionnaire was given to the elderly, those over 65 years old, along with our constant guidance because of their advanced age and for improved elaboration, whereas the HADS was given to adults between 18 and 65 years old. Although HADS could be administered to both groups of patients, due to the poor education level of the elderly patients $(>65)$ visiting the health centers in Cyprus, GDS was preferred due to the simple "yes/no" structure of the responses. All respondents were asked to self-report the percentage reduction in their income. The participation of the respondents was strictly anonymous and highly respected while giving them the option to voluntarily participate in the survey.

The study's sample consisted of 300 adults, 150 adults over 18 years old to 65 (HADS Scale), and 150 elderly people aged over 65 (GDS Scale). Participants were patients who visited the RHC Kofinou during the period from July to September 2015 and were selected with a random sampling method. 


\section{Statistical Analysis}

Demographic characteristics and total scale scores are presented as frequency $(\mathrm{N})$ and proportion (\%) for categorical variables (i.e., gender, education level, anxiety and depression levels, etc.) and mean \pm standard deviation for the continuous variables (i.e., age and total scale scores). Multivariate analysis for the adjusted effect of the demographic factors was conducted using linear regression models on total emotional distress, level of stress, and level of depression for the HADS scale and on total depression score for the GDS scale. The factor reduction in earnings was also included in the multivariate analysis and was determined by the investigators at $35 \%$ for the HADS scale and at $20 \%$ for the GDS scale, as these cutoffs represent the mean self-reported reduction level in the two samples, respectively. All analyses were performed with the social science analysis package SPSS (IBM Corp. Released 2012. IBM SPSS Statistics for Windows, Version 21.0. Armonk, NY, USA).

\section{Results}

\subsection{Sample Characteristics}

The study based on the HADS scale involved 150 patients; 84 (56\%) were female. The mean age of the participants was $47 \pm 11.5$ years, with a minimum age of 23 years and a maximum of 64 . The study based on the GDS scale sampled another 150 patients. Seventy-seven (51.3\%) were women. The average age of participants is $72 \pm 5.5$ years old, with a minimum and a maximum age of 66 and 90 years old, respectively. Fifty-three (35.3\%) participants believed they showed signs of depression after the economic crisis (Table 1). The demographic and clinical characteristics of both samples are shown in Table 1.

Table 1. Demographic and clinical characteristics of the sample that completed the Hospital Anxiety Depression Scale (HADS) $(n=150)$ and Geriatric Depression Scale (GDS) $(n=150)$ scale.

\begin{tabular}{|c|c|c|c|c|c|}
\hline \multicolumn{2}{|c|}{ Variables } & \multicolumn{2}{|c|}{ HADS Scale } & \multicolumn{2}{|c|}{ GDS Scale } \\
\hline & & $\mathbf{n}$ & $\%$ & $\mathbf{n}$ & $\%$ \\
\hline \multirow[t]{2}{*}{ Gender } & Woman & 84 & $56.0 \%$ & 77 & $51.3 \%$ \\
\hline & Man & 66 & $44.0 \%$ & 73 & $48.7 \%$ \\
\hline \multicolumn{2}{|l|}{ Age } & \multicolumn{2}{|c|}{$\begin{array}{c}47 \pm 11.5 \text { years } / \mathrm{MIN}=23 \\
\mathrm{MAX}=64\end{array}$} & \multicolumn{2}{|c|}{$\begin{array}{c}72.9 \pm 5.5 \text { years } / \mathrm{MIN}=66 \\
\mathrm{MAX}=90\end{array}$} \\
\hline \multirow{6}{*}{ Education level } & None & 0 & $0.0 \%$ & 11 & $7.3 \%$ \\
\hline & Primary School & 32 & $21.3 \%$ & 99 & $66.0 \%$ \\
\hline & Secondary & 12 & $8.0 \%$ & 17 & $11.3 \%$ \\
\hline & Lyceum & 63 & $42.0 \%$ & 19 & $12.7 \%$ \\
\hline & Higher Education & 35 & $23.3 \%$ & 4 & $2.7 \%$ \\
\hline & Master/PhD & 8 & $5.3 \%$ & 0 & $0.0 \%$ \\
\hline \multirow{6}{*}{ Annual income } & Unemployed & 15 & $10.0 \%$ & 0 & $0.0 \%$ \\
\hline & Until 8000 & 46 & $30.7 \%$ & 100 & $66.7 \%$ \\
\hline & $8001-12,000$ & 21 & $14.0 \%$ & 30 & $20.0 \%$ \\
\hline & $12,001-18,000$ & 25 & $16.7 \%$ & 13 & $8.7 \%$ \\
\hline & $18,001-30,000$ & 26 & $17.3 \%$ & 6 & $4.0 \%$ \\
\hline & 30,001 and over & 17 & $11.3 \%$ & 1 & $0.7 \%$ \\
\hline \multirow{2}{*}{\multicolumn{2}{|c|}{$\begin{array}{l}\text { Reduction of the annual income due to } \\
\text { economic crisis in the last year } \\
\text { Presence of chronic disease }\end{array}$}} & 116 & $77.3 \%$ & 93 & $62.0 \%$ \\
\hline & & 70 & $46.7 \%$ & 139 & $92.7 \%$ \\
\hline \multicolumn{2}{|c|}{ Blood hypertension } & 42 & $60.0 \%$ & 100 & $66.7 \%$ \\
\hline \multicolumn{2}{|c|}{ Diabetes } & 22 & $31.4 \%$ & 58 & $38.7 \%$ \\
\hline \multicolumn{2}{|c|}{ Lipid disorder } & 28 & $40.0 \%$ & 73 & $48.7 \%$ \\
\hline \multicolumn{2}{|c|}{ Autoimmune disease } & 0 & $0.0 \%$ & 1 & $0.7 \%$ \\
\hline \multicolumn{2}{|c|}{ Heart disease } & 7 & $10.0 \%$ & 32 & $21.3 \%$ \\
\hline \multicolumn{2}{|c|}{ Other } & 12 & $8.0 \%$ & 4 & $2.7 \%$ \\
\hline \multicolumn{2}{|c|}{$\begin{array}{l}\text { Do you believe you have symptoms of } \\
\text { depression after the economic recession? }\end{array}$} & - & - & 53 & $35.3 \%$ \\
\hline
\end{tabular}




\subsection{HADS Scale}

The overall HADS scale (total emotional distress) and sub-factors anxiety and depression showed excellent internal consistency index (Cronbach's alpha $=0.921,0.821,0.813$ respectively).

The average total HADS scale was $16.8 \pm 8.9$, with a possible maximum of 42 . The average level in the subscales anxiety and depression was $9 \pm 4.8$ and $7.8 \pm 4.5$, respectively, with a possible maximum of 21 . As shown in Table 2, $43.3 \%$ of the research's participants have normal stress levels and $50 \%$ normal depression levels.

Table 2. Level of anxiety and depression-HADS $(\mathrm{N}=150)$.

\begin{tabular}{ccccc}
\hline Variables & \multicolumn{2}{c}{ Anxiety Level } & \multicolumn{2}{c}{ Depression Level } \\
\hline & $\mathrm{n}$ & $\%$ & $\mathrm{n}$ & $\%$ \\
Normal Level & 65 & $43.3 \%$ & 75 & $50.0 \%$ \\
Mild Level & 30 & $20.0 \%$ & 32 & $21.3 \%$ \\
Moderate Level & 35 & $23.3 \%$ & 31 & $20.7 \%$ \\
Severe Level & 20 & $13.3 \%$ & 12 & $8.0 \%$ \\
Total & 150 & $100 \%$ & 150 & $100.0 \%$ \\
\hline
\end{tabular}

Normal levels (total score 0-7), Mild (8-10), Moderate (11-14), Severe (15-21).

\subsection{HADS Multivariate Analysis}

There were three linear regression models (adjusted demographically) on the following dependent variables: emotional distress (total scale score), level of stress, and level of depression (Table 3).

Table 3. Regression analyses of emotional distress, anxiety, and depression on the socioeconomic factors.

\begin{tabular}{|c|c|c|c|c|c|c|}
\hline \multirow{2}{*}{$\begin{array}{c}\text { Dependent Variable } \\
\text { Predictors }\end{array}$} & \multicolumn{2}{|c|}{$\begin{array}{l}\text { HADS-Total Score } \\
\text { (Emotional Distress) }\end{array}$} & \multicolumn{2}{|c|}{ HADS-Anxiety } & \multicolumn{2}{|c|}{ HADS-Depression } \\
\hline & $b^{*}$ & $p$ & $b^{*}$ & $p$ & $b^{*}$ & $p$ \\
\hline (Constant) & 25.6 & $<0.001$ & 14.098 & $<0.001$ & 11.502 & $<0.001$ \\
\hline Age & -0.059 & 0.445 & -0.039 & 0.355 & -0.019 & 0.621 \\
\hline Gender (women) & -2.058 & 0.138 & -1.296 & 0.094 & -0.762 & 0.274 \\
\hline Chronic disease & 5.449 & $<0.001$ & 2.817 & 0.001 & 2.632 & 0.001 \\
\hline Annual Income & -1.066 & 0.017 & -0.642 & 0.01 & -0.425 & 0.058 \\
\hline Education Level & -2.633 & $<0.001$ & -1.196 & 0.003 & -1.436 & $<0.001$ \\
\hline Reduction in earnings ( $>35 \%)$ & 2.917 & 0.063 & 1.177 & 0.178 & 1.741 & 0.028 \\
\hline \multicolumn{7}{|l|}{ Model fit indices } \\
\hline $\mathrm{F}$ ( $p$ value) & \multicolumn{2}{|c|}{$11.309(<0.001)$} & \multicolumn{2}{|c|}{$8.986(<0.001)$} & \multicolumn{2}{|c|}{$11.696(<0.001)$} \\
\hline Adjusted $\mathrm{R}^{2}$ & \multicolumn{2}{|c|}{0.293} & \multicolumn{2}{|c|}{0.243} & \multicolumn{2}{|c|}{0.301} \\
\hline
\end{tabular}

* Unstandardized beta weights.

The possible range of HADS anxiety and HADS depression is $0-21$; for emotional distress, $0-42$. The regression analysis showed that patients with chronic disease have higher anxiety levels by 2.82 units $(b=2.82, p=0.001)$, depression by 2.63 units $(b=2.63, p=0.001)$, and emotional distress by 5.45 units $(b=5.45, p<0.001)$.

Moreover, an increase in the annual income category is associated with an average of 0.64 units less in the level of anxiety $(b=-0.64, p=0.01)$ and 2.63 units less in the emotional distress level $(b=-2.63, p<0.001)$.

Every additional level of education is associated with an average of 2.63 units less in the level of emotional distress $(b=-2.63, p<0.001), 1.18$ units less in the anxiety level $(b=-1.196, p=0.003)$, and 1.44 units less in the depression level $(b=-1.436, p<0.001)$.

Finally, a reduction in income in excess of $35 \%$ is associated with an increase in the depression levels by 1.74 units $(b=1.74, p=0.028)$ in the HADS-depression sub-scale. 
Further investigation revealed that a reduction in income in the excess of the mean reduction level of $35 \%$ is moderately associated with a lower annual income category $\left(x^{2}=9.027, p=0.032\right)$. People in the lower income categories reported a more significant reduction in their annual income than in the higher income categories.

\subsection{GDS Scale}

The overall GDS scale showed an adequate internal consistency index (Cronbach's alpha $=0.691$ ). The average geriatric depression of the 150 participants was $5.77 \pm 4$, with an observed minimum and maximum 0 and 15 , correspondingly.

\section{Reference to Depression Symptoms}

Based on the questionnaires, 35.3\% $(n=53 / 150)$ of the participants reported that the economic crisis was the provoking factor of their depressive symptoms.

The findings revealed that $29 \%$ of the participants denied having depression, although they fulfilled the diagnostic criteria of the syndrome according to the GDS scale (i.e., GDS $\geq 7$ ). In 71\% of cases, the responses coincided with the GDS scale. In other words, the respondents denied having depression, and this was supported by the scale findings.

According to the GDS, a similar phenomenon occurs in people who initially reported having symptoms of depression, while $36 \%$ of these individuals are ultimately not depressed (Figure 1).

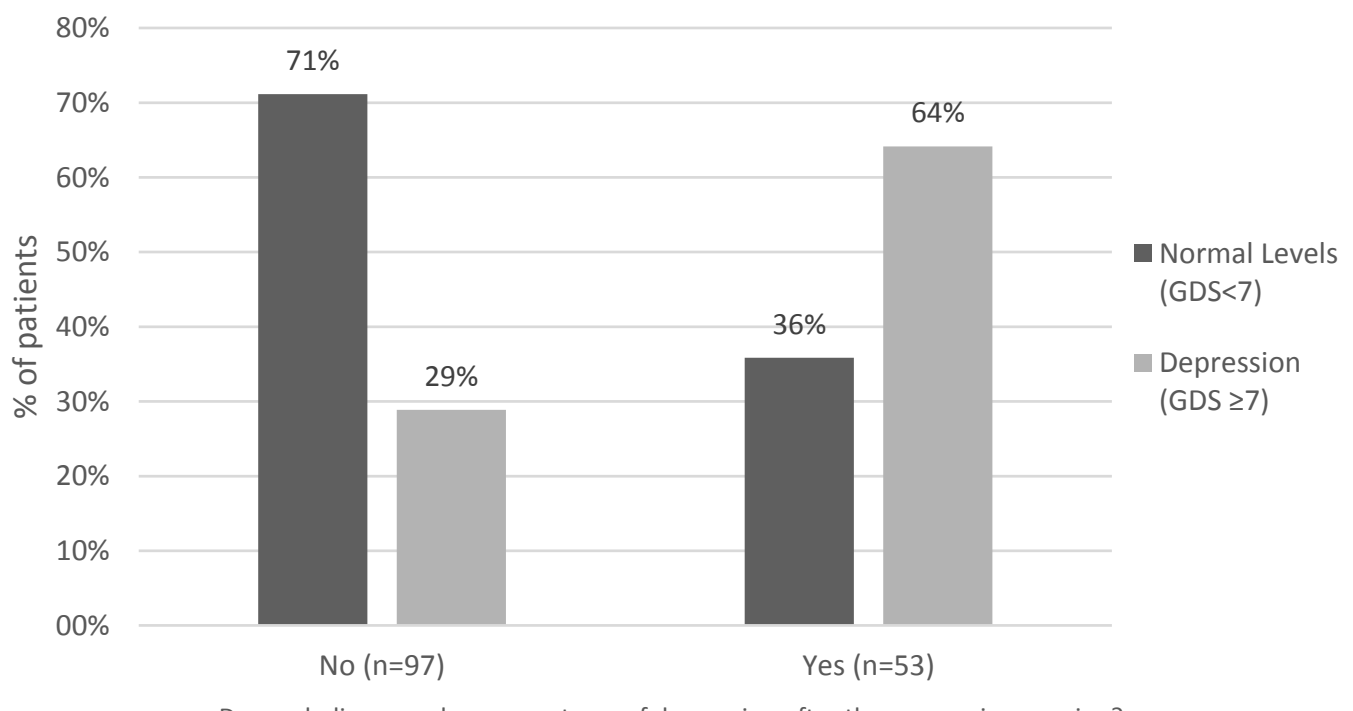

Do you believe you have symptoms of depression after the economic recession?

Figure 1. Self-reported depression symptoms vs. depression according to the GDS Scale ( $\geq 7$ ).

\subsection{GDS Multivariate Analysis}

A linear regression model was applied to adjust the effect of the demographic characteristics in the participants' total GDS score.

The regression analysis (Table 4) shows that men have lower levels of geriatric depressive symptoms than women by almost 2 points on average on the GDS scale $(b=-1.96, p=0.005)$. Additionally, for every additional year in their age, elderly patients have higher depressive symptoms by 0.16 points on average on the GDS $(b=0.16, p=0.006)$. Education, the presence of chronic disease, and the reduction in the people's salaries beyond the mean reduction level of $20 \%$ do not seem to be associated substantially with the level of geriatric depressive symptoms. It is also observed that annual income is not statistically associated with the level of geriatric depression. This is probably due to the high association of gender and income, as women in this sample are 1.92 times more likely to belong 
to the lowest income category of below $€ 8000(\mathrm{n}=67 \%-87 \%)$ than men $(\mathrm{n}=33 \%-45 \%)\left(\mathrm{x}^{2}=32.7\right.$, $p<0.001)$.

Table 4. Regression analyses of total GDS score on the socioeconomic factors.

\begin{tabular}{cccccc}
\hline Variables & $\mathbf{b}$ & $\mathbf{S E}$ & Standardised $\mathbf{b}$ & $\mathbf{t}$ & $\boldsymbol{p}$ \\
\hline (Constant) & -5.338 & 4.505 & & -1.185 & 0.238 \\
Gender (female) & -1.958 & 0.687 & -0.248 & -2.849 & 0.005 \\
Age & 0.161 & 0.058 & 0.223 & 2.778 & 0.006 \\
Annual income: & -0.703 & 0.39 & -0.153 & -1.801 & 0.074 \\
Chromic disease & 1.279 & 1.149 & 0.084 & 1.113 & 0.267 \\
Reduction in earnings $(>20 \%)$ & 0.739 & 0.665 & 0.086 & 1.112 & 0.268 \\
\hline
\end{tabular}

Note: SE = Standard Error; Dependent variable: Total GDS score, $\mathrm{F}=6.552, p<0.001$, Adj $\mathrm{R}^{2}=0.17$.

\section{Discussion}

Our findings are supported by two different studies [11,12], which delineate the important association between gender and mental health.

In addition, Marmot et al. points out that people with lower social status are twice as likely prone to mental disorders [13]. This finding agrees with the results of this study, as demonstrated by the educational level factor. Precisely, it was illustrated that the more educated the citizen is, the less anxiety, depression, and general emotional distress they may experience [14].

Additionally, the key factor of the economic recession is the annual income decrease for each individual. Giotakos believes that reduced income, reduced labor specialization, and social alienation have shown to be associated with negative effects on physical, emotional, and psychological health, as well as an increased risk of low life expectancy [9]. His views also reinforce investigations carried out by Economou et al., which correlated unemployment rates with causes of death (studied six causes of death) at a very high percentage (83.33\%) [15]. Within the same survey, it was also indicated that the patient's financial well-being is associated with less anxiety, depression, and emotional distress.

Falagas et al. demonstrated the significant relationship between chronic disease and mental health [16]. The patients who suffer from chronic diseases tend to have higher levels of anxiety, depression, and general symptoms of emotional distress compared with non-patients.

Methodological weaknesses that emerged during the course of this investigation were as follows:

(a) Appropriate comprehension of the questionnaires by the participants, especially in cases where the patients were uneducated, could not be guaranteed. Senior citizens required guidance throughout the process, either because of a low educational level or because of a physical disability.

(b) This is a cross section of data and thus we cannot interpret any of our findings as causal or generalize for the whole population. It is vital to obtain information from the general population, as this study is limited to people who sought medical help.

\section{Future Recommendations}

Several researchers within the health sector have recognized the importance of a human's mental health and well-being. Mental illness has been a very frequent phenomenon in the Cypriot community in the last few years. However, few studies, if any, have dealt with this crucial issue. Furthermore, as this is a cross-sectional study and no causal inferences can be made on the associations that were identified, further investigation on the drivers of emotional distress to the population should be performed, and additional concurrent stressors that could explain the depression or anxiety levels should be explored. 


\subsection{Political Authority}

Each country's health sector is undoubtedly a foremost issue that needs exceptional attention. Politicians must address the whole situation with interest by setting future goals, hence dealing and solving problems that may arise. Unfortunately, the health system in Cyprus has many weaknesses, which come at the expense of the country's citizens. An important function of the state is the lack of political will. The state ought to set laws in order to better address such distressing situations by carrying out administrative procedures as soon as possible with the aim to better resolve arising issues.

\subsection{Health Practitioners}

In an effort to fight mental illness, health professionals need to form a group that will be responsible for the prevention of mental disease and public information. They can also organize seminars to sensitize the Cypriot community and raise awareness of the severity of this situation. Furthermore, various stereotypes and prejudices regarding depression syndromes must be gradually eliminated from Cypriot society.

\section{Conclusions}

The study shows that stress levels, depression, and emotional distress are increased in specific population groups. The main variables associated with the mental health of the participants are the presence of chronic disease, income, and level of education. There are also strong indications that reductions in earnings might be an additional stress factor.

Author Contributions: Eleni Jelastopulu conceived of the idea for the current study and collaborated with Georgios Charalambous in order to provide Georgios Stavrou with proper guidelines; Georgios Stavrou implemented the idea in order to fulfill the study's objectives. Precisely, Georgios Stavrou distributed the questionnaires at the Rural Health Centre Kofinou, and the statistical analysis of the data collection was carried out by Lefkios Paikousis; Georgios Stavrou wrote the paper.

Conflicts of Interest: The authors declare no conflict of interest.

\section{References}

1. Michopoulos, I.; Kalkavoura, C.; Michalopoulou, P.; Fineti, K.; Kalemi, G.; Psara, M.L.; Gournelis, R.; Christodoulou, C.; Douzenis, A.; Patapis, P.; et al. Hospital Anxiety and Depression Scale at General Hospital (HADS): Validation in a Greek hospital sample. Ann. Gen. Psychiatry 2008, 7. (In Greek). [CrossRef] [PubMed]

2. Fountoulakis, K.; Tsolaki, M.; Iacovides, A.; Yesavage, J.; O’Hara, R.; Kazis, A.; Ierodiakonou, C. The validation of the short form of the Geriatric Depression Scale (GDS) in Greece. Aging Clin. Exp. Res. 1999, 11, 367-372. [CrossRef]

3. Ng, K.; Agius, M.; Zaman, R. The effects of economic crisis on mental health. Eur. Psychiatry 2011, 26, 663. [CrossRef]

4. Mousoulos, S. The Santums of the Economic Crisis in Cyprus; Epiphaniou Publications: Nicosia, Italy, 2014. (In Greek)

5. Burchell, B. Social change and the experience of unemployment. In The Effects of Labour Market Position, Job Insecurity and Unemployment on Phychological Health; Gallie, D., Ed.; Oxford University Press: Oxford, UK, 1994.

6. Stuckler, D.; Basu, S.; Suhrcke, M.; Coutts, A.; McKee, M. The public health effect of economic crisis and alternative policy responses in Europe: An empirical analysis. Lancet 2009, 374, 315-323. [CrossRef]

7. Paul, K.; Moser, K. Unemployment impairs mental health: Meta-analyses. J. Vocat. Behav. 2009, 74, $264-282$. [CrossRef]

8. WHO. Impact of Financial Crisis on Health: A Truly Global Solution Is Needed. Available online: http://www.who.int/mediacentre/news/statements/2009/financial_crisis_20090401/en/ (accessed on 24 January 2015).

9. Giotakos, O. Financial Crisis and Mental Health. Eur. Psychiatry 2010, 21, 195-204. 
10. Siklaphidou, P.; Zeleni, D.; Leivaditis, M. Transcultural Psychiatry and Depression. Brain Arch. Neurol. Phychiatry 2011, 48, 146-150. (In Greek).

11. Spyropoulou, A.; Zerva, G. Introduction to "Woman and Mental Health". Available online: https:// entosfylou.wordpress.com/ (accessed on 28 October 2015). (in Greek).

12. Kantartzis, S. Disorders. Available online: http://www.kanartzis-soterios.gr/html/katathlipsi.html (accessed on 28 October 2015). (In Greek).

13. Marmot, M. Status Syndrome: How Your Social Standing Directly Affects Your Health and Life Expectancy; Bloomsbury Publishing Plc: London, UK, 2004.

14. Blane, D. Commentary: Explanations of the Difference in Mortality Risk between Different Educational Groups. Int. J. Epidemiol. 2003, 32, 355-356. [CrossRef] [PubMed]

15. Economou, A.; Nikolaou, A.; Theodossiou, I. Are recessions harmful to health after all? Evidence from the European Union. J. Econ. Stud. 2008, 35, 368-384. [CrossRef]

16. Falagas, M.E.; Vouloumanou, E.K.; Mavros, M.N.; Karageorgopoulos, D.E. Economic crises and mortality: A review of the literature. Int. J. Clin. Pract. 2009, 63, 1128-1135. [CrossRef] [PubMed]

(C) 2016 by the authors; licensee MDPI, Basel, Switzerland. This article is an open access article distributed under the terms and conditions of the Creative Commons Attribution (CC-BY) license (http://creativecommons.org/licenses/by/4.0/). 